\title{
The Research of the Inheritance and Protection of QuJing Zhuang Folk Dance
}

\author{
Qiaogui Xu \\ College of music and dance, Qujing Normal University, Qujing, Yunnan, 655011 \\ qjsfxyxqg@126.com
}

Keywords: Zhuang; Folk dance; Protect the inheritance; Innovation and development

\begin{abstract}
The folk dance as a national soul, how to still play the effect of strength in the modern, make it adapt to the development of the current, thus better and protect the heritage, has become an important topic of the present study. In this article, through one of the typical folk dance - qujing zhuang folk dance for the special case, to explore the actuality of zhuang nationality folk dance, through specific case to explore the basic way of protection and inheritance.Inheriting the zhuang folk dance on national non-material cultural heritage protection and inheritance, for the construction of socialist culture and a harmonious society has important significance.
\end{abstract}

\section{Introduction}

Dance as a unique form of art, in the continuous development of society, forming a unique art form and both social and artistic aesthetic form, is the majority of people in the social practice of the inspiration and performance. In order to show the social customs of a certain region, passing the local cultural and artistic feelings, to bring pleasure to enjoy. And folk dance is as the basis for performance of the local customs, religious beliefs, customs, and other series, inheritance of the essence of Chinese traditional dance. [1] however with the development of history, due to improper protection and inheritance, lost many folk dance, so on Chinese ethnic and folk dance is the inheritance and protection becomes more and more urgent. Qujing is an area inhabited by many nationalities and minorities 8 (Han, Yi, Hui, Miao, Buyi, Zhuang, Shui, Yao), Zhuang as Qujing Ju one of seven minority nationalities, is also the most diverse resources of the nation. The folk dance of the Zhuang nationality is the root of the Zhuang nationality. It is the embodiment of the spirit and soul of the Zhuang nationality. It is an important part of the Chinese nation's outstanding culture."

\section{Qujing Zhuang folk dance research background.}

Qujing Zhuang nationality region analysis. Qujing District, Zhuang, mainly distributed in the Nanpanjiang Basin at the southern tip of Shizong, Luoping County, the northern tributary of Jinsha River Kraal River on both sides of the Huize, Xuanwei City. [3] nationality of Shizong County, and is mainly distributed in the Wulong, high yield, Long Qingsan Xiang, Dong and Guangxi Xilin County, across the river, the South even Wenshan Qiubei County, Luxi County, Honghe Prefecture, in the West and on the north of Shizong Datong, Choi Wan Xiang. Has a long history of the development process, as well as a variety of cultural and artistic resources. In this form of development of Qujing Zhuang folk dance in a variety of folk art charm, become China's important "intangible cultural heritage", once the promotion and protection, however, with the impact of globalization, China's folk dance is greatly affected by the regional characteristics of the Zhuang folk dance once lost its unique artistic characteristics. Therefore, strengthening the protection of the national dance in the region of the Zhuang nationality is the inheritance and promotion of local ethnic cultural heritage, and carry forward the Chinese traditional culture. [4]

Value and significance of research. (1)The value of the study. The national folk dance pass out the national culture, especially to be a kind of communication symbol can better play the national development, the traditional folk dance can strengthen our love and development of national culture, 
the world's culture is the national culture, the existence of the national culture, to which we should show the national cultural value, enhance and promote the national identity and pride.

(2)The significance of the study. The difference between the folk dance and other dance is that it has a strong regional and national character. Although some elements in the course of history will gradually fade or disappear, but its folk characteristics and cultural elements and leading the people's psychological elements will remains down, and inheritance. The folk dance of the Zhuang nationality is colorful, and it has a strong foundation in the people's communication. It is like a flower blooming flowers, in the long river of national culture. [5]

\section{Folk dance of Qujing -- the research of Zhuang dance}

National analysis. Qujing's national folk dance is the biggest characteristic of national character, it from many angles to explore the charm of national culture, played a better role in inheritance, Qujing area is a farming based region, agricultural occupy a very important position, so people living labor is the most important one of the unique form of dance, local culture, and local unique geographical location has become a form of dance art form. [6]

The characteristics of the folk dance of the Zhuang Nationality in Qujing. (1)One of the characteristics of the dance of the Zhuang nationality". In ancient times, it was full of worship to God, which is also reflected in the dance, as a unique form of the region. [7]

(2)Two "imitation of the characteristics of the dance of the Zhuang nationality". Labor is the best embodiment, dance is usually imitate the daily life of labor, whether animal imitation or evident in daily life of running, jumping, Liuma and become dance based action elements.

(3)Three characteristics of Zhuang dance entertainment. In the Zhuang folk dance, every festival, Zhuang people in the region will organize a variety of activities, and dance is the most can reflect the festive atmosphere, the use of music to express the joy of the heart, and anyone can participate in it, to feel the charm of folk dance culture. Simple to learn the dance moves, so more entertaining. This kind of kindness and enthusiasm has attracted many tourists, and felt the pleasure of art and dance, but also promoted the development of regional tourism. [8]

The artistic charm of the folk dance of the Zhuang Nationality in Qujing. Dance of the farming period is wove and promote love niuhu farming content. Many dance and Folk Customs together and with God pray for peace and pray for good weather. There are also great differences in the types of folk dance, which need us to explore and research. Famous for its work and love. [9], including bronze drum dance, dance club, handkerchief, bowl dance, horse dance dance "etc.. Is characterized by draw extensively on a variety of styles of dance, including a variety of Shigong and witch dance, is the performance of labor life. Zhuang is very good at singing, dance performances in many times is a combination of songs.

\section{The protection and inheritance of folk dance}

The use of education to achieve national folk dance Heritage. The power of culture is not to be estimated, to create and build national culture needs to start from the national interests, to establish a scientific concept of the construction of national culture, will carry forward the main body of the Zhuang folk dance into the teaching system, and realize the continuation of the national culture. This shows that the combination of national culture and education is particularly important. A clear direction and identify the position, give full play to regional advantages, concise research, strengthen cooperation and build to contribute to seeking support, in contribution for development, will become the base construction of Inheriting Ethnic Music and dance culture of base, base of cultivating talents spreading, base of scientific research base of ethnic music and dance, to serve the local cultural construction, through the base of the platform provides fundamental condition for the research of matching funds and security. The way to rely on education is not only an important choice but also the inevitable choice of the future. The folk dance of the Zhuang nationality is a very bold innovation in the classroom. The power of education is very strong, in the study of 
imitation, to solve the ideological problems of education. Imitation and inheritance of in the monasteries, carry forward from the broad base in Zhuang dance.

The renewal of the concept of Education. The students' ideas of the new main in the national folk dance with the identity, if the introduction of the primary school classroom to the popularization of compulsory education in nine years to improve the dance features. In short in the heritage and the recipient must follow the concept of national culture. To understand and love the local culture, to cultivate them from many angles to observe and cultivate art and culture. Culture of national identity and acceptance of belonging. There is a consensus in the formation of the folk dance in the leadership, teachers, and students as well as the whole society. Full national identity is the national quality of the whole nation and the prosperity and development of the whole society. From all aspects of the concept, to promote the development of national dance.

Improving teaching conditions. To improve the entertainment facilities in the society and to make full use of the advantages, to make use of the advantages to develop the school resources reasonably, especially in the school art class. Use of professional materials and equipment, for professional teachers' configuration, to take the way of resource cooperation. To overcome difficulties, with the curriculum and materials for the construction of students, to strengthen the exchange and interaction between the school. 2 modern forms of folk dance of the Zhuang Nationality in Qujing.

Qujing Zhuang folk dance experienced from ancient ancestor worship, to the era of agricultural worship to the God cow, many forms of dance has not, but a lot of traditional spirit remained in the. In the new era, the integration of the spirit of the times, to create a new form of national dance. The Zhuang people in ancient times maintained the infinite awe to the nature, and thought that the nature of nature in the dance inspired by the infinite power, so that the elements of the dance would tend to be natural. In the period of agriculture dance is more to the image of Nandi as a totem and worship object, life people bovine care better, people think that the presence of cattle that makes people progress, help the Zhuang people farming work. The progress of history on the elements of dance let gratitude more and more in the dance form. Humanistic environment in Yunnan Qujing area feature rich, simple folkway attracted many tourists come here, in the form of dance transfer and expression more features. Now the content of Zhuang dance has changed but the spirit of the same, the tradition of the same, the Zhuang people use the way of dance to sing the progress of life. Mainly in the following areas:

(1) The dance factor and the local cultural reconstruction mutually agree with each other, in the process of the modernization society's development to realize the national culture and the reform mechanism. The development of dance industry culture chain is also the innovation and change from the traditional to the modern. This kind of culture is in accordance with the development law of the history, the development trend of the modern society, the integration of the elements of dance culture and cultural reconstruction, provides a new opportunity for the development of local dance culture. In the traditional elements of the traditional discovery of modern reform, to adapt to the new era of development trends.

(2) Starting from the practice of regional development, in order to explore the essence of national culture, to find a new situation and new changes in the two. National culture is the product of the combination of multiple factors, and it is the capital that is formed during the process of the practice. $\mathrm{Ma} \mathrm{Yu}$ believes that "national culture is increasingly being used as a means of resources or a tool for the continuous changing of the people of the life mode of choice to provide material may. National culture and economy is mutual penetration, can not be separated, with the characteristics of chimeric, this chimeric enable national culture can be used as a resource tool in the production of modern society Zhongbo abandoned in order to win the competitive advantage. "

(3) The inheritance mode of dance culture. Qujing Zhuang folk dance in the cultural heritage of the people of life and nature of love, thousands of years in the dance of the Zhuang people in the region is difficult to break through, in the material civilization, the Zhuang folk dance has been a great challenge, but it is a reflection of regional characteristics, the development of Zhuang dance how to get out of the bottleneck is our important consideration, how to keep the traditional dance is 
not forgotten, is a thorny issue. Can draw on the new trend of culture, in keeping the tradition of dance based on the combination of the spirit of the times, to speed up the development of dance, to the public to the world. Zhuang's cultural heritage is a large part of the dance, dance experts should continue to collect and collate the precious dance form, leaving the photo image, in order to keep it more real. First, the cultural content in the education carrier on the integration of more harmonious, combined with the local education situation to prepare teaching materials. Tracing to its source, the diversity of culture significance and bring the value of far more than the imagination and the creativity of art form and artistic re creation, for art to bring fresh blood. This paper expounds the unique charm and artistic nature of national culture, and gives a new vitality to the national dance.

Play the role and value of market in the development and inheritance of culture. Improve the role of the market in the local development, the use of the development trend of the market to better play the national culture of dance. Under the condition of market economy, the role of market plays a leading role, so it can reduce the intensity of government decision-making, clear the role of service or in government, enterprise, the members of the Zhuang nationality region to achieve the cultural innovation. Promote local tourism and economic development. To form a market oriented role, a clear market positioning, according to the choice of the market, to seek their own development is the socialist market economy requirements. Starting from the market, according to the public's joy to hear the good news of its development trend, so that better heritage.

Regions and the government to play its effectiveness. "The government should strengthen the protection and inheritance of national folk dance, establish a dynamic and static way, and establish the folk protection and inheritance mechanism. Together with the government and civil society, the publication of folk dance audio and video materials, books. Hold the national song and dance music, ethnic costumes, ethnic handicrafts, etc., to create a national culture brand, organize the expert team to further research and heritage, strengthen exchanges and cooperation, improve the protection and construction system." Zhuang folk dance as a cultural product, its development process is a very long exploration, the need for each level is not only the national authorities, local governments, experts and scholars, the regional people, enterprises and other aspects of the common efforts to achieve. In order to realize the inheritance and innovation of culture, we can get better protection.

To develop the national folk dance, we must keep pace with the times and innovate spirit. We must grasp the relationship, and keep the original ecological dance. We can not only combine with the modern trend, but also lose the original flavor. All in all, the Qujing Zhuang folk dance should have the unique artistic form of the regional characteristics, to further explore and find the way to the future development.

\section{Reference}

[1]PengJinsongExploration on Multiple Cultural Characteristics and Social Value of Chinese Natio nality Sport Dance, ournal of Beijing University of Physical Education,2006(8).

[2] YuanGe. Research on the Cultural Characteristics and the Fitness Value of Waving Dance of Tujia Nationality.Chongqing Social Sciences,2005(4).

[3] Huang Xiaoming,Chen Limin, Primitive Remains" and Its Developing Trend in the Inheritance of Folk Dance of the Zhuang Nation, Arts Exploration Journal, 2008(6).

[4] Yao Xiaolan Research on the Correlation of Nationality and Regionality of Education in Multinational Areas.Southwest University,2007.

[5] Tantao.Investigation on Cultural Actuality and Successive Strategies of Waving Dance in Tujia Nationality[D].Southwest University,2008.

[6] Liu Shujun.Research on the Artistic Feature of Primitive Dance of Ethnic Group in Yunnan, Journal of Qujing Normal University,2009(2). 
[7] Heming. The arts in the Marketized Performance, Beijing:Social Science Documentation Publishing House,2011.

[8] Huang Shuping,Gong Peihua.Research on the Theory and Method of Cultural Anthropology , Guangdong Higher Education Press,2004.

[9] HuHuilin.Introduction to cultural industry, KunMing:YunNan University Publishing House,2005.71-83. 